\title{
An Energy Efficient Renewable Power Supply System with Power Regeneration equipped in a UAV
}

\author{
Minu Theresa Mathew ${ }^{1}$ \\ Lecturer, AMA International University, College of Engineering, Salmabad, Bahrain ${ }^{1}$
}

\begin{abstract}
Renewable energy resources can be used as the power supply source in a number of applications. Unmanned aerial vehicle which can be used in a number of applications like military, surveying, rescue and disaster management can be equipped with hybrid energy systems like fuel cell and PV system which can provide sufficient supply for long distance flight plans. The proposed paper focuses on the implementation of a hybrid system with a regeneration technique implemented in the motor connected at the output of the power supply. The power supply can be taped from the PV cell during the flight during the day time. A fuel cell connected can be connected to drive the motor during the time when there is less sunlight. The regenerative technique implemented takes the mechanical output of the motor in the form of kinetic energy and convert it into the electrical energy. Regenerative braking can be implemented in the flight during the time the load requirements are less and the motor can be used for regenerative purposes. Thus increasing the efficiency and overall performance of the vehicle.
\end{abstract}

Keywords: UAV, Hybrid System, PV Panel, Fuel Cell, Regenerative Braking

\section{INTRODUCTION}

Renewable energy harvesting is an ever booming field with unlimited possibilities. A hybrid system employed on many electronic and electrical devices work well with any systems connected to it with high efficiency. A typical hybrid system consisting of a pv cell or fuel cell is easy to implement and does not have much operating cost. In order to save our future from the blackouts and energy crisis in the near future, more importance must be given to the harvesting of renewable energy and designing of energy efficient hybrid models. The paper focuses on the development of a power supply system which can be implemented in an unmanned aerial vehicle. Since the power is drawn from the renewable energy sources, the energy is clean and can be developed economically considering the requirements. The paper also focuses on the selection of the components to be implemented in the system. UAV's are used in a number of applications like in surveying, military, rescue, disaster management etc. The power supply to drones is very critical for its efficient operation. A hybrid system like PV system and fuel cell implemented to aerial vehicles can be economical and to increase the efficiency the power regeneration technique can be implemented at the output of the device. The mechanical output of the motor can be regenerated from the motor shaft and stored in the batteries for the use. PV cell topologies can be well used in the countries of the Arabian peninsula. Renewable energy is a ever growing future technology. This research paper can be a boon to the renewable energy field and can be a way to construct a drone utilizing hybrid power which is more economical after the research the propose scheme can be commercially mass produced. A $\mathrm{n}$ efficient drone with power regenerative capability is desired.

The study [1] concentrates on fuel cell system and PV cell hybrid model. A conventional power supply system employed in an unmanned vehicle is a typical fossil fuel. The conventional system has many disadvantages as it limits the total fuel that can be employed as well as the system causes environmental pollution. A PV panel and fuel cell implemented can be used for the flight but as the weight factor is important the system has limitations. Rechargeable batteries store energy but the efficiency is not fully justifiable for long flight paths. The model was an economical model but it has limitations for long distance travel, owing to the fact that fuel cell is having longer responsive time. The battery is employed during the time the demand is maximum.

The model which has fuel cell system cannot be realised for long range applications as there is a weight limiting factor involved in the design. [3].

Rechargeable batteries can also be employed in the hybrid system which can store the energy produced by the fuel cell and the additional energy generated from the PV array system [7].The implemented system provide an average of 500 $\mathrm{W}$ power and during the start of the flight provide $800 \mathrm{~W}$. The initial response time required for the fuel cell can limit the performance of the UAV during the take off. [8]. 


\title{
International Advanced Research Journal in Science, Engineering and Technology
}

\author{
Vol. 6, Issue 3, March 2019
}

an Unmanned aerial vehicle can be used in applications which requires intense scrutiny into localised regions and can be implemented in applications like military, remote sensing surveying etc. Unmanned vehicle is also termed as remote vehicle with no pilots on board. A number of methods can be advocated in the remote vehicles as a power supply system like capacitors, renewable energy resources like PV system which can tap the energy from the photons and utilize the same for the power generation. Since the PV panels are implemented weight factor for the design is not compromised [2].

The hybrid model proposed in [4] provides a combustion fuel engine and a motor. The model in itself was not found to be efficient for long distance travel. The flight duration can also be limited in this case. If the combustion engine is used in the vehicle the efficiency is as limited as $25 \%$. A very long range flight can be made possible with the power system implemented in paper[5]. The model has a disadvantage that it cannot meet up with the load requirements during start up. The main reason for not meeting up with the load requirements id that fuel cell has slow initial response time [6]. Paper[9] provides a very simple method using which braking can be done in an electric motor like brushless dc motor and power regeneration can also be implemented in the motor. No additional requirements are required for the scheme as converters or capacitors are not required. The kinetic energy from the motor shaft ends are converted to electric energy and returned to the supply mains or to the battery which can be used for any requirements for the vehicle. It was found out that the driving limit of the vehicle was increased up to $16 \%$. The paper[10] implemented the use of fuel cell in the technology of UAV design a fuel cell of small capacity as small as $100 \mathrm{~W}$ was implemented in the model. The testing of the model proved that the design can be implemented in a UAV for a long endurance flight plan. The power provided was sufficient for the machine to have small controlling actions. An efficient system which uses the power supply with less cost is implemented in paper[11]. The power supply system consists of PV system and fuel cell and can be used to electrify a village in India. The paper[12] uses a boost converter topology with dual input that can be implemented in hybrid power supply systems and has a comparatively high efficiency. Paper[13] deals with the implementation of hybrid system with the permanent magnet DC motor load and a control system is also implemented for the efficient operation of the system.

\section{STATEMENT OF THE PROBLEM}

an unmanned aerial vehicles which work on hybrid power with high efficiency with less robust parts and flight capacity is the main challenge in the proposed paper. Since the paper focuses on improving the efficiency the idea of regenerative power from the motor shaft can be employed. The regenerative power from the motor shaft cannot be implemented risking the durability and lightness of the craft design. The more economical and efficient components are to be employed for all the parts of the hybrid vehicle which includes a pv panel, more durable and economical fuel cell, boost converter, a bi directional converters and the ways to tap the output from the motor shaft and convert it into the electrical energy which can be used to fly the drone when there is no sunlight for the pv panels to work. So the realization of the entire scheme with more economical layout without risking the lightness of the design is the biggest research challenge. A mechanism known as regenerative braking can be implemented in the electric motor where in the motor works as a generator and the speed of the motor can be reduced as the speed is reduced the vehicle can be used for descend as the torque required for the descending is less than the ascending. When the vehicle is supplied with a power supply system the efficiency of the device during take off and descending is important so that concept is covered in the study.

\section{A. Significance of the study}

This study will provide specific information about the implementation of hybrid systems which can be used as an efficient power supply systems .Renewable energy power generation is going to be the next big thing in the coming years, as the current power generation schemes are dependent on the depleting energy sources. In future the survival of the humans might depend on the utilization of these renewable energy sources. Therefore, the awareness in the community will increase towards the ways of power generation using renewable energy and increasing its efficiency. The university's research thrusts geared towards advancement of knowledge and understanding, and sustainable development, and a research in the field of power generation using renewable energy and making the system efficient. As the hybrid system of power supply is implemented a number of backup power supply systems are also implemented in the design that can conserve and hold the power for the flight path.

\section{B. Scope and Limitations}

The study is mainly focused on the development of a hybrid model which can be used for a long and efficient flight path. The hybrid model is based on PV cell and fuel cell. The model can be implemented as a power supply system where in the fuel cell can be used during the time when there is no sun light and PV cell can be implemented during day time. A regenerative system implemented in the system at the output can make the system more efficient. The main limitation of the model is the weight factor as the power supply system is to be implemented in an unmanned aerial 


\section{International Advanced Research Journal in Science, Engineering and Technology}

Vol. 6, Issue 3, March 2019

vehicle where flight duration and efficiency depend upon the light loading of the vehicle. The implementation of the system for power regeneration is another challenging factor.

The principle goal of the paper is to develop an efficient drone (un manned aerial vehicle) with a boost converter using a hybrid system comprising of fuel cell and PV system and can convert the power output from the motor to the useful energy to be stored in the battery.

1) Develop an efficient, durable and justifiable model for an unmanned aerial vehicle.

2) Implement power regeneration techniques from the motor shaft and obtain the output with the help of simulations.

\section{Definition of Terms}

Photo voltaic panel: an array of $\mathrm{P}$ cells which can be implemented to convert photons or light energy to electrical energy.

Hybrid energy system: a hybrid energy system consists of one or two renewable energy source conversion system like PV array- fuel cell system

UAV: an unmanned aerial vehicle which can be used in a number of applications like military, surveying etc.

Fuel cell: a cell which converts the chemical energy from the fuel into electrical energy with the help of a chemical reaction between hydrogen and oxygen or an oxidizing element.

BLDC motor: a brush less DC motor is a synchronously rotating motor which works on DC electricity is supplied through an inverter which can give rise to an alternating current using which the phases of the motor works.

\section{THEORETICAL AND CONCEPTUAL FRAMEWORK}

A brushless dc motor OR an induction motor is a desirable motor for the electric motor because of its high efficiency. By tying the output of the motor directly to the battery storage the power can be regenerated or by implementing methods like regenerative method the regeneration can be implemented in the model.

A.

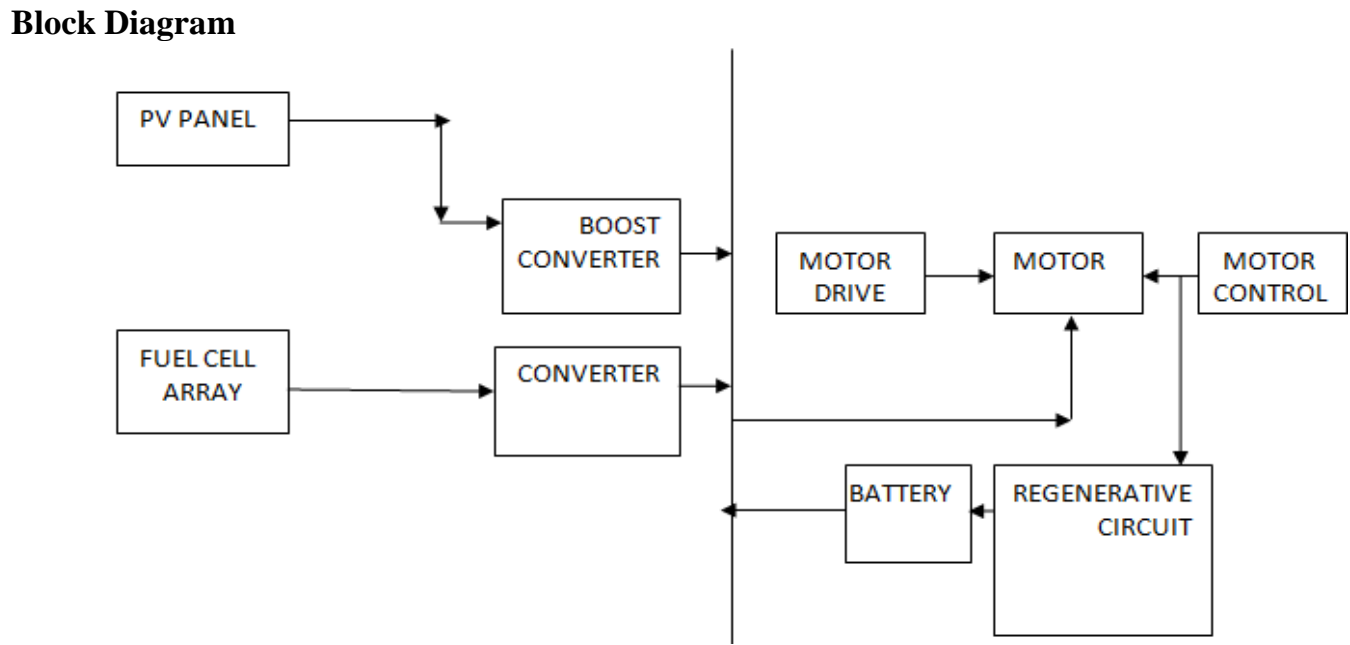

Figure 1: Block Diagrammatic Representation of the Power Supply System

The system to be implemented consists of a hybrid system which makes use of a fuel cell and PV panel system. Since the power supply is to be implemented in an unmanned aerial vehicle, the components and renewable system selected should be having light weight. PV panel's generated voltage is given to a boost converter which can increase the input voltage to a greater level. a battery can be incorporated in the design as the battery system can store voltage and release the voltage when the power is required.

The concept of regenerative braking can be implemented in the model. In this method the kinetic energy or the mechanical energy from the output of the motor is fed back to the power supply mains. This method can be implemented when the machine is forced to run at a speed greater than the no load speed as the load connected to the motor demands the motor to work at higher speeds. The back EMF of the motor will be greater than the supply voltage under these conditions i.e., $\mathrm{E}_{\mathrm{b}}>\mathrm{V}$. The machine now starts to work like a generator supplying power to the mains. For a typical 0.5 Horse power DC motor with a rotor having a weight of around $2 \mathrm{~kg}$ and a radius of rotor as $6 \mathrm{~cm}(0.06 \mathrm{~m})$ 


\section{International Advanced Research Journal in Science, Engineering and Technology}

Vol. 6, Issue 3, March 2019

The moment of inertia can be given as

$\mathrm{I}=1 / 2 * 2 *(0.06)^{2}=0.0036 \mathrm{kgm}^{2}$

For a motor rotating at $3600 \mathrm{rpm}$ (revolutions per minute)

3600 revolutions per minute $=60$ revolutions per second

The kinetic energy is:

$\mathrm{KE}=1 / 2 *(0.0036) *(60 * 3.14 * 2)^{2}$

$\mathrm{KE}=255$ joules

This can be taken equal to charging a battery of voltage 12 at an ampere of 20 for a time of 1 second. This factor can be considered for the regeneration of electrical power.

\section{B. Regenerative Braking Design}

The regenerative braking is a mechanism that can recover energy at the output by slowing the motor and the recovered energy can be used immediately or stored for later use. the process of regenerative braking requires a set of motor/ generator and the pair of motor/ generator is employed to convert the kinetic energy developed in the motor's rotor side and convert the kinetic energy to the electrical energy using the generator employed. a battery system can be employed to store the electric energy and can be used for the flight period of the unmanned aerial vehicle. the efficiency of the motor/ generator set can be computed using the formula

$$
\text { efficiency } \mathrm{n}=\text { power output,power input. }
$$

But the weight factor of these components can limit the efficiency of the unmanned vehicle. since the generator used will add up the load.

In the unmanned aerial vehicle this method is not used to halt the motor- generator set employed but it is mainly employed to slow down the speed of the motor in the aerial vehicle required for some applications in the unmanned vehicle. Any type of motor can be used in the configuration but the BLDC motor or PMSM is the most desired configuration.
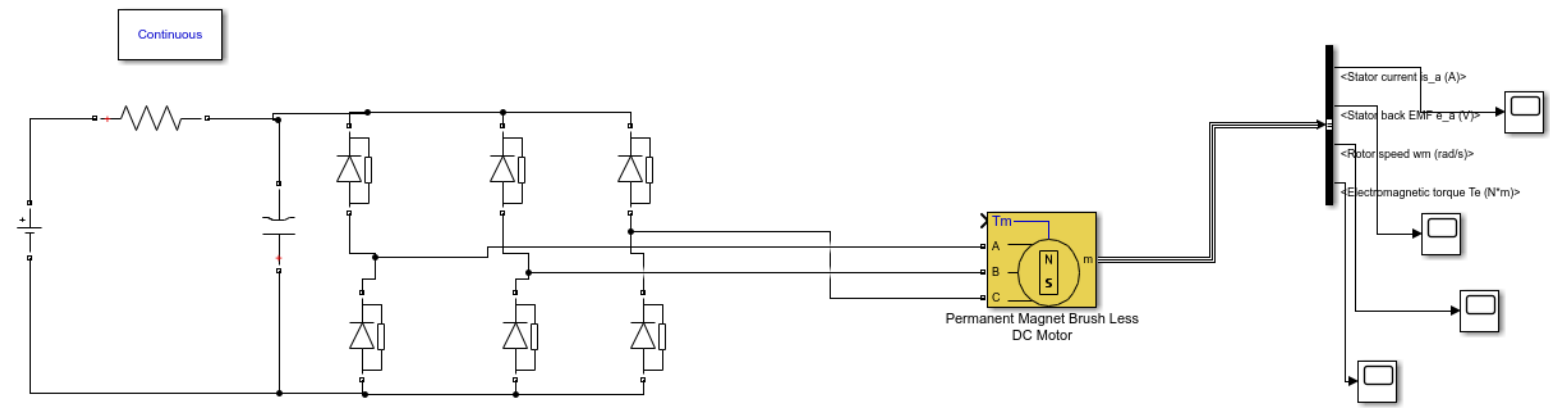

Figure 2: Regenerative braking circuit for BLDC motor

For the regenerative switching circuit individual circuit six power switches are connected back to back. Each leg operates one by one which gives the input to BLDC motor and drives the motoring action to the generating action which can be connected to a battery in the input. The input resistance connected controls the amount of current passing through the circuit.

\section{Fuel Cell stacking model}

The fuel cell stack is simulated with the available model of $1.26 \mathrm{kw}, 24 \mathrm{v}$ dc supply. the adopted model is efficient for an unmanned aerial vehicle as the payload is limited for the pv cell stacks and fuel cell efficiency can be maximised for the effective operation of the model.

A single fuel cell in the model can produce a voltage of 0.6 to $0.7 \mathrm{~V}$. Inorder to increase the performance of the hybrid system a $100 \mathrm{~V}$ DC-DC boost converter is connected to the output of the fuel cell stack. 
Vol. 6, Issue 3, March 2019
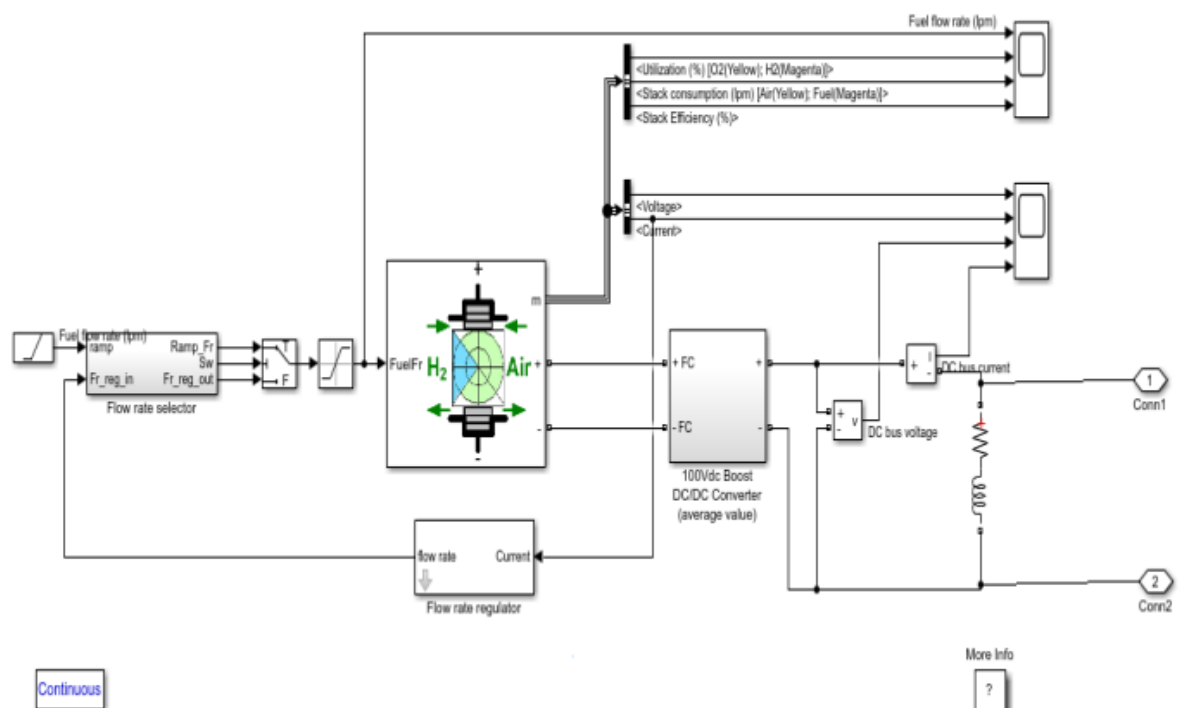

Figure 3: Fuel Cell Stack System

\section{Hybrid Model of PV Cell- Fuel Cell}

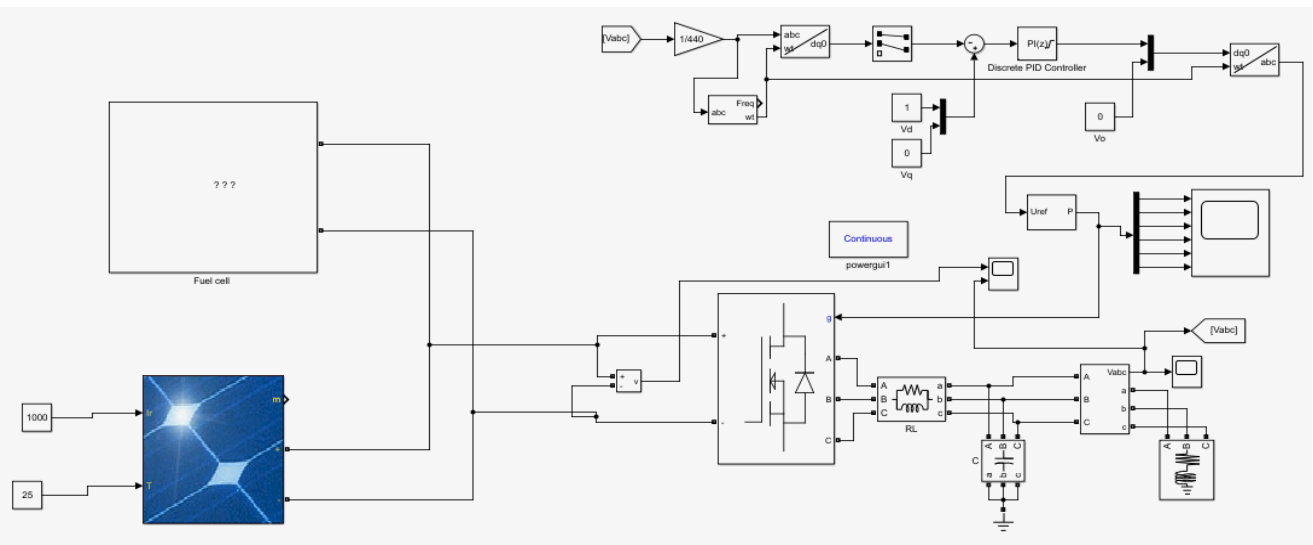

Figure 4 :Hybrid model of PV Cell- Fuel Cell

The hybrid power supply model consists of a PV cell array and fuel cell connected together. For the PV module stack 1 Soltech 1 STH-215-P is used with parallel strings of pv cells and arrays. A universal bridge is connected to the output of the PV array and the fuel cell hybrid system. A discrete PID controller is connected to the circuit to control the system. A three phase load is connected to the output.

\section{E. Model of Hybrid system without braking system}

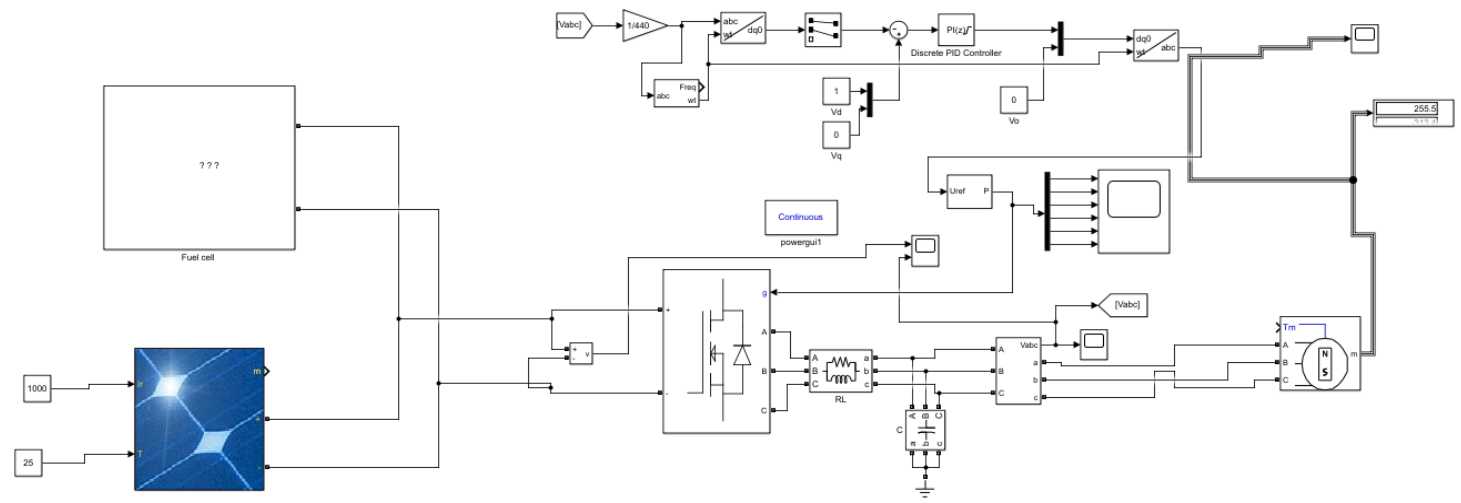

Figure 5: Model of Hybrid System Connected to Motor Without Braking. 


\section{International Advanced Research Journal in Science, Engineering and Technology}

Vol. 6, Issue 3, March 2019

\section{F. Data Analysis}

A flow rate regulator and a flow rate selector is implemented in the fuel cell stack.

Nominal hydrogen utilization in $\%=65 \%$

Operating temperature in Celsius $=65$ degrees

Fuel pressure $=1.5$ bar

Hydrogen composition $=99.95 \%$

Rating of the boost converter used $=100 \mathrm{~V} \mathrm{DC} / \mathrm{DC}$ converter

Fuel cell stack used is PEMFC - 1.26 KW- 24 V Stack

\section{G. PV Module}

PV array used = 1 Soltech 1 STH-215-P with parallel strings and arrays

Maximum power of array module $=213.15 \mathrm{~W}$

Open circuit voltage $=36.3 \mathrm{~V}$

Voltage at maximum power point $=26 \mathrm{~V}$

Short circuit current $=7.83 \mathrm{~A}$

Current at maximum power point $=7.35 \mathrm{~A}$

\section{H. Methods of Analysis}

The analysis is conducted by analysing the MATLAB model which involves the hybrid model of PV cell and fuel cell conjugated together to feed the Unmanned aerial vehicle. The output voltage of the hybrid system and the braking system will be considered for the analysis and depending on the output obtained with and without the braking system the conceptual framework can be proved. The resulting waveforms can be evaluated to analyse the performance of the system as a whole.

\section{Complete model}

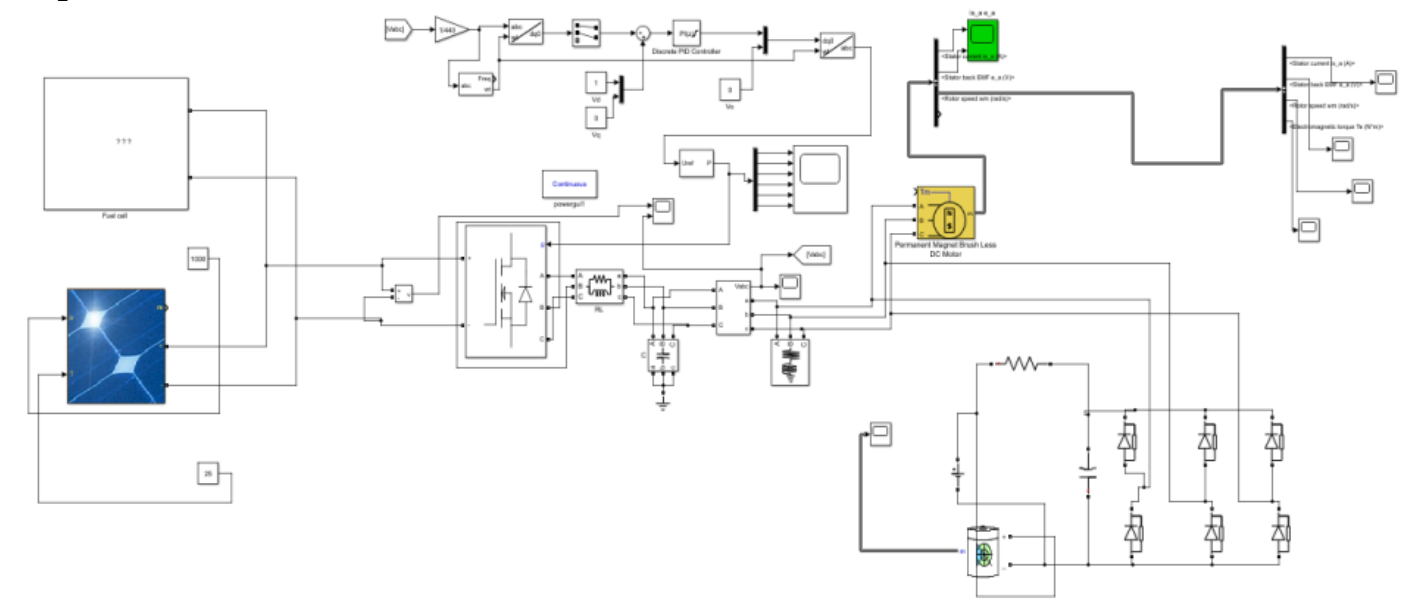

Figure 6: Complete hybrid system with regenerative braking

The complete model comprises of the hybrid model of PV array and fuel cell conjugated together as power sources each equipped with its own boost converter topologies within the subsystem represented in the circuit diagram. The output of the hybrid system is directly connected to a universal bridge which outputs a three phase voltage in response to the output obtained from the hybrid system which is dc supply. The motor employed is a PMBLDC motor which has a drive mechanism and controller system employed to effectively control the mechanism. The output of the motor is also fed back to the regenerative mechanism which forces the motoring action to the generating action which is in turn stored in a battery for further usages whenever required.

\section{J. Motor Outputs}

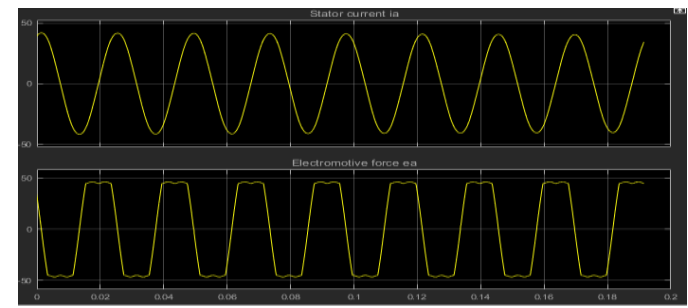

Figure 7: Motor outputs 
Vol. 6, Issue 3, March 2019

Upon the analysis of the output obtained as stator current denoted as ia, is found to e around $40 \mathrm{~A}$ and around $80 \mathrm{~A}$ peak to peak. The electro motive force was found to be around $48 \mathrm{~V}$ and $96 \mathrm{~V}$ peak to peak for the machine. The motor was working under full load and it was found out that the armature current and electro motive force were found to be sufficient under the given load conditions. If the load is varied the armature current and torque requirements will vary accordingly.

\section{K. Output Voltage of the hybrid model}

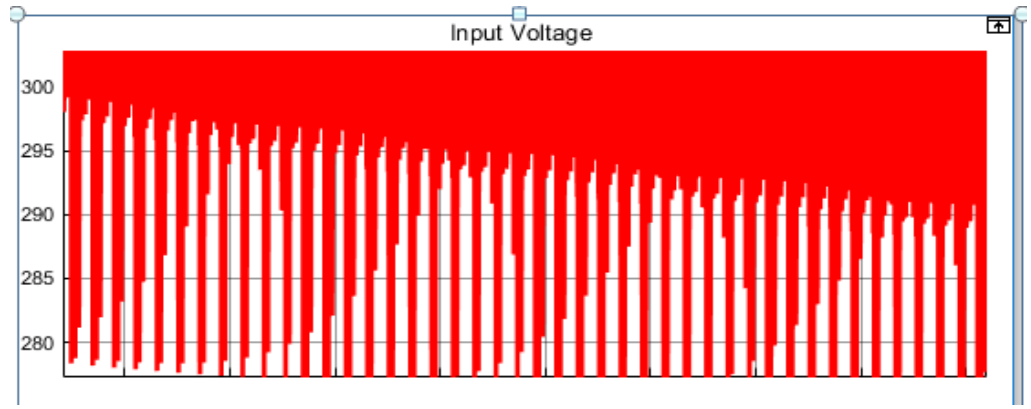

Figure 8: Complete output voltage of the hybrid model

The output voltage of the hybrid model was found to be fluctuated where time was varying. With a proper stabilization the fluctuation can be controlled with improvisation in the design features. In addition to this the universal bridge connected in the output of the system gives uniform voltage distribution for the hybrid model. The maximum output voltage across the hybrid model was found to be around $300 \mathrm{~V}$.

\section{Output Voltage of a Universal Bridge}
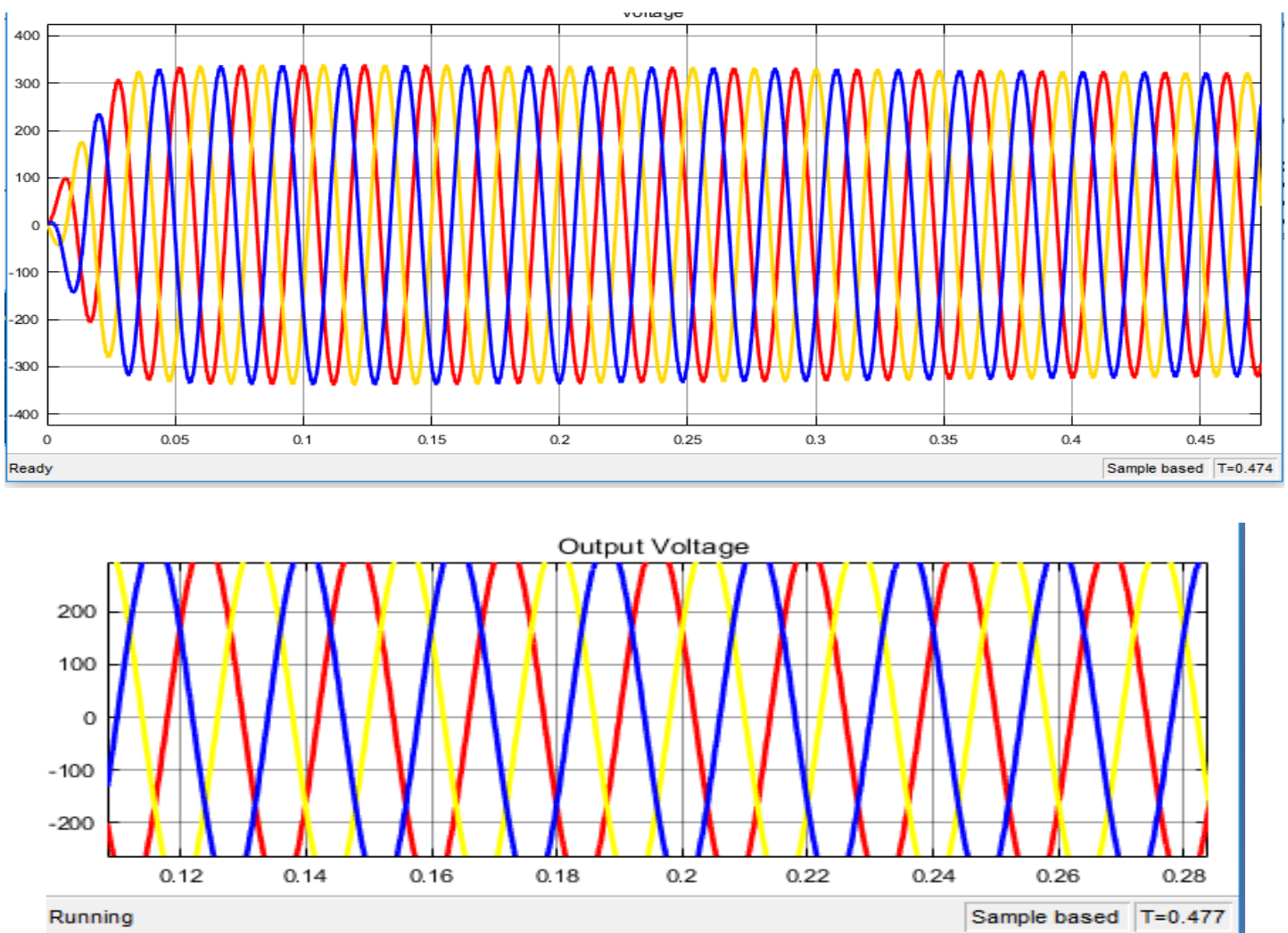

Figure 9: Output Voltage of Universal Bridge

The universal bridge connected at the output of the hybrid model is employed mainly to give out a three phase voltage at the output of the circuit. The bridge configuration utilizes six power switches. The voltage across each of the bridge legs can configure a three phase supply voltages which is specified with different colors like red, blue, yellow. The output 3 phase voltage obtained is around $320 \mathrm{~V}$. The voltage initially is damped and gradually builds up and reaches up to $320 \mathrm{~V}$ 


\section{International Advanced Research Journal in Science, Engineering and Technology}

Vol. 6, Issue 3, March 2019

M. Regenerative circuit output

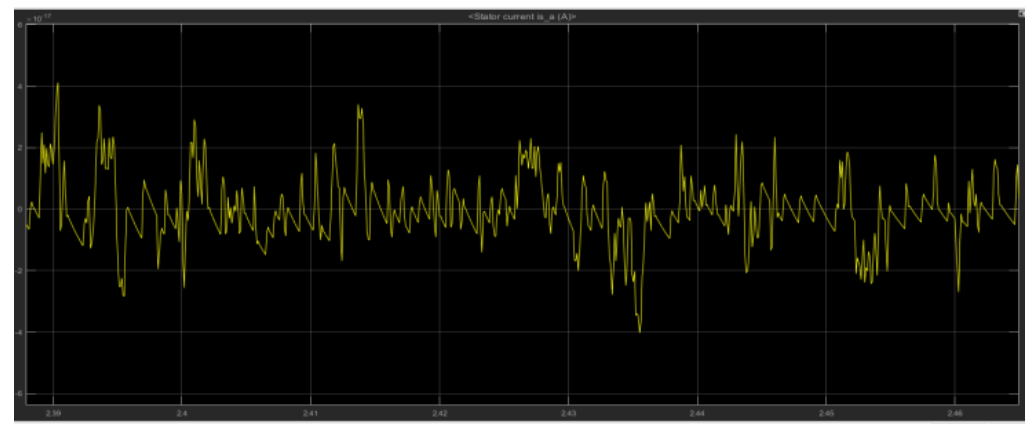

Figure 10: Regenerative braking output

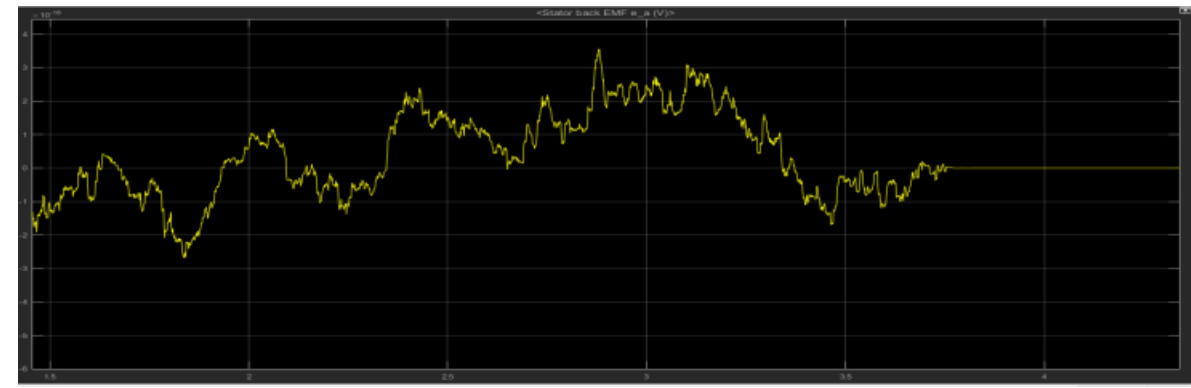

Figure 11: Detailed diagram of motoring and braking

Figures above clearly illustrate the operation of motoring and generating action of the motor connected. The power switches connected drives the motor to a generator above a particular speed of operation of motor.

\section{CONCLUSION}

Hybrid systems can be effectively employed in drone applications and the power regeneration system can be implemented with good levels of efficiency. The determining factors of the model are the type of PV panel and fuel cell selected in the view point of the load to be carried in the machine and performance parameters. The regenerative braking mechanism slows the motor down, can be employed during the down flight of the UAV in the direction of gravity and can additionally drive the motor from the motor from the motoring to the generating action which can be indeed given back to the system if the motor is to be operated again using the battery source as well as the hybrid system employed. The model was found to be cost effective since generators or other heavy equipments were not involved. Since hybrid system is employed in the UAV, the model has economy factors and since two renewable energy systems are conjugated together. Since PV panel is employed the device can work efficiently during the day time and for applications after day time fuel cell can be employed. The efficiency factor is further boosted up with the regenerative mechanism employed. Transients were prevalent in the output of the motor which can be stabilized by appropriate drive mechanism and control mechanism for the motor. The regenerative mechanism can be automated and sensors can be conjugated to detect the in flight and other applications of UAV

\section{REFERENCES}

[1]. Hybrid Energy Storage System for Unmanned Aerial Vehicle (UAV) Hao Chen, Student Member, IEEE, and Alireza Khaligh, Senior Member, IEEE Energy Harvesting and Renewable Energies Laboratory (EHREL); Electrical and Computer Engineering Department; Illinois Institute of Technology; 3301 S. Dearborn St. Chicago, IL 60616;

[2]. A. Emadi and M. Ehsani, "Aircraft power systems: technology, state of the art, and future trends," IEEE Aerosp. Electron. Syst. Mag., vol. 15, Sep. 2000, pp. 28-32.

[3]. Committee on Materials, Structures, and Aeronautics for Advanced Uninhabited Air Vehicles, National Materials Advisory Board, Aeronautics and Space Engineering Board, Commission on Engineering and Technical Systems and National Research Council, Uninhabited Air Vehicles: Enabling Science for Military Systems," National Academy Press, ISBN: 0-309-06983-1, 2000.

[4]. R. R. Glassock, "Multimodal hybrid power plant for unmanned aerial systems (UAS) robotics," in 24th Bristol International Unmanned Air Vehicle Systems Conf, Bristol U.K., March 2009, pp. 15-20

[5]. T. M. Lam, “Aerial Vehicle,” In-Tech Press, ISBN: 978-953-7619-41-1, 2009.

[6]. B. P. Loop and S. D. Sudhoff, "Analysis and simulation of a UAV power system," in Power System Conf., Jan. 2002, pp.31-38.

[7]. M. Michon, J. L. Duarte, M. Hendrix, and M. G. Simoes, "A three-port bi-directional converter for hybrid fuel cell systems," in Proc. IEEE 35th Power Electron. Spec. Conf., Aachen, Germany, Jun. 2004, pp. 4736-4742.

[8]. Alireza Khaligh and Omer C. Onar, "Energy Harvesting: Solar, Wind, and Ocean Energy Conversion Systems," CRC Press, ISBN: 978-14398-1508-3, 2009. 


\section{International Advanced Research Journal in Science, Engineering and Technology}

Vol. 6, Issue 3, March 2019

[9]. Modeling of a hybrid system of photovoltaic and fuel cell for operational strategy in residential use-Y. Hidaka; K. Kawahara $2012 \quad 47$ th International Universities Power Engineering Conference (UPEC) Year: 2012

[10]. Ming-Ji Yang, Hong-Lin Jhou, Bin-Yen Ma, and Kuo-Kai Shyu, Member, IEEE “A Cost-Effective Method of Electric Brake With Energy Regeneration for Electric Vehicles".

[11]. Marco Klaus F"urrutter, Johan Meyer "Small Fuel Cell Powering an Unmanned Aerial Vehicle" Cost and size optimization of solar photovoltaic and fuel cell based integrated energy system for un- electrified village" Manish khemariya, Arvind Mittal, Prashant Baredar, Anant singh Journal of Energy storage December 2017

[12]. "A stand- Alone Hybrid PV-Fuel Cell Power system using Single- Inductor Dual Input Single output Boost converter with model predictive control”, Benfei Wang,Liang Xian, Ujjal Manandhar, Jian Ye, Hoay BEng Gooi.Asian conference on energy ,power, and transportation October 2017.

[13]. "Performance of Solar PV- Fuel cell for stand alone applications", T Ramesh,L Darunprasanth,S Kaliappan, G Emayavaramban, International Journal for Engineering and Technology April 2018

\section{BIOGRAPHY}

Minu Theresa Mathew received the B.S. and M.S. degrees in Electrical Engineering from Mahatma Gandhi University and Anna University India in 2009 and 2012 respectively. She has done extensive research in power electronics and renewable engineering field. She is now working in AMA university Bahrain 